Original Research Paper

\title{
Superovulation Response and Embryo Quality Recovered Following Flushing Nguni Heifers and Cows
}

\author{
${ }^{1}$ Ayanda Maqhashu, ${ }^{2}$ Masindi L. Mphaphathi, ${ }^{5}$ Pokgedi J Sebei, \\ ${ }^{3}$ Voster Muchenje and ${ }^{2,4}$ Tshimangadzo L. Nedambale \\ ${ }^{1}$ Department of Animal Sciences, University of Pretoria, Lynnwood Rd, Hatfield, Pretoria, 0002 \\ ${ }^{2}$ Agricultural Research Council Irene Campus, Old, Olifantsfontein Rd, Irene, 0062 \\ ${ }^{3}$ University of Fort Hare, Department of Livestock and Pasture Sciences, Private Bag X1314, Alice, 5700, RSA \\ ${ }^{4}$ Department of Animal Sciences, Tshwane University of Technology, Staatsartillerie Rd, Pretoria West, Pretoria, 0183 \\ ${ }^{5}$ Limpopo Department of Agriculture, Mara Research Station, Private Bag X 2467, Makhado, 0920
}

\section{Article history}

Received: 04-08-2021

Revised: 01-10-2021

Accepted: 14-10-2021

Corresponding Author: Ayanda Maqhashu Department of Animal Sciences, University of Pretoria, Lynnwood Rd, Hatfield, Pretoria, 0002 Email: maqhashua@gmail.com

\begin{abstract}
The aims of the study were to compare super ovulatory response, fertilization rate and evaluate embryo quality recovered from super ovulated Nguni stud cows and heifers. Nguni cows $(n=15)$ and heifers $(n=10)$ aged 4-6 and 2 years, respectively, were used as embryo donors. Embryo donors were synchronized for estrus before superovulation. For superovulation donors were administered with $350 \mathrm{mg}$ of FSH (Folltropin ${ }^{\circledR}-\mathrm{V}$ ) divided into 2 injections daily $12 \mathrm{~h}$ apart for 4.5 days on a decreasing dosage. Semen was collected from two Nguni bulls (bull 1 and 2) using an Electro Ejaculator (EE) and semen characteristics (volume, motility, viability, concentration and morphology) were recorded and motility parameters were assessed by computer aided sperm analysis before Artificial Insemination (AI). Donor cows and heifers were inseminated randomly with semen straws from either bull 1 or bull 2 . Embryos were flushed 7 days after AI using a nonsurgical technique and were evaluated under microscope for quality. Data were analyzed using one-way ANOVA and linear or quadratic relationships were used to determine effects of semen traits on fertilization rate and embryo quality. No significant differences were observed on the super ovulatory response rate of Nguni cows and heifers $(\mathrm{P}>0.05)$. Furthermore, no significant differences were recorded on fertilization rate between cows (67.5\%) and heifers (63.5\%) (P>0.05). Embryo quality between Nguni cows (code 1, 2.5 \pm 1.00 ; code 2, 1.3 \pm 0.59 ) and heifers (code 1, 0.8 \pm 0.41 ; code 2, 1.0 \pm 0.36 ) was similar. There was no significant difference between bull $1(93.7 \%)$ and bull 2 (90.5\%) on total sperm motility rate $(\mathrm{P}>0.05)$. The Super ovulatory response, fertilization rate and embryo quality between Nguni cows and heifers was similar.
\end{abstract}

Keywords: Corpus Luteum, Embryo Quality, Sperm Motility

\section{Introduction}

The Nguni cattle breed is an indigenous breed of South Africa known for its excellent mothering ability, high fertility with a long productive life under harsh environmental conditions and has very low mortality rates from birth to weaning (Nqeno et al., 2010; Nedambale, 2012). It is a low input and maintenance breed, tolerant to most tick-borne diseases, parasites and reaches sexual maturity early, particularly in heifers (Tada et al., 2013). However, Nguni cattle breed genetic material has been degraded over the years due to perceptions that it is inferior to exotic breeds due to its smaller body size and varied color patterns. Given the global challenges of climate change and drought it is an ideal breed for sustainable agriculture in Southern Africa and loss of this breed would not only reduce options for dealing with climate change and increasing food demands but also negative social and cultural impacts.

Multiple ovulation and embryo transfer is a crucial tool for the implementation of genetic improvements and conservation programs of endangered animals. It is the method of choice for germplasm control. However, its utilization is limited due to it being expensive and 
variability that exists in predicting the quality and quantity of transferable embryos that will be recovered. The inconsistency in ovarian response has been attributed to many other factors such as genetic factors, nutrition, age, season, dynamics in follicular growth and gonadotrophin preparations (Bertens, 2010; Hasler, 2010). Furthermore, Baruselli et al. (2006) reported that successful embryo production is also affected by poor conception rates caused not only by female factors but also reduced fertilizing capacity of the spermatozoa due to preservation procedure or poor quality bulls. A bull with poor sperm motility rate generally indicates a limitation to accomplish fertilization. The spermatozoa can be analyzed for motility and viability using Computer Aided Sperm Analysis $\left(\mathrm{CASA}^{\circledR}\right)$ system before Artificial Insemination (AI). Sperm motility has been reported to be a good predictor of conception rates (Seshoka et al., 2016). Most of available information on superovulatory response in beef cattle has been obtained from mostly the Bos Taurus breeds with very limited information on Bos indicus breeds. Degefa et al., (2016) reported that biological differences exist in reproductive function between Bos taurus and Bos indicus cattle with respect to age at puberty, oestrous cycle patterns, oestrous behavior, acquisition of ovulatory capacity, ovarian structures and reproductive hormone production. Hence, the objectives of the study were to compare superovulatory response, fertilization rate and to evaluate embryo quality recovered from super ovulated Nguni cows and heifers.

\section{Materials and Methods}

\section{Experimental Site}

The study was conducted at the Agricultural Research Council's (ARC) Animal Production (AP), Irene, Republic of South Africa. The location of the campus is $25^{\circ} 53^{\prime}$ 58' 'South; 28 11 ' $52^{\prime}$ ' East and is in the Highveld region of South Africa at an altitude of $1524 \mathrm{~m}$ above sea level. The climatic conditions in this environment range from hot days to cool nights in summer to a moderate temperature on winter days with cooler nights. The average temperatures at Irene range from 4.6 to $28.0^{\circ} \mathrm{C}$. The region is coldest during July when the temperature drops to an average temperature of $1.7^{\circ} \mathrm{C}$.

\section{Embryo Donors}

Experimental animals were cared for according to the guidelines of the ARC-AP ethics committee (APIEC13/007). Nguni stud cows $(n=15)$ and heifers $(n=10)$ aged 4-6 and 2 years respectively were selected following pregnancy diagnosis and examination of the reproductive tract for abnormalities and diseases. The cows and heifers had an average body weight of $350 \mathrm{~kg}$ and $210 \mathrm{~kg}$, respectively.

\section{Oestrous Synchronization and Superovulation of Nguni Cows and Heifers}

Nguni donor cows and heifers followed the same oestrous synchronization and superovulation protocol whereby a controlled internal drug releases device $\left(\mathrm{CIDR}^{\circledR}\right)$ (1.9g, Pfizer (Pty) ltd, Sandton, Republic of South Africa) was placed into the vagina of each cow and/ heifer on Day 0. An intramuscular injection (i.m) of Cloprostenol Sodium $\left(263 \mu \mathrm{g}\right.$, Estrumate ${ }^{\circledR}$, Isando, RSA) was administered (i.m) to the cows and heifers after CIDR $^{\circledR}$ removal on Day 8 . An intramuscular injection of estradiol benzoate ( $1 \mathrm{~g}$ Pfizer (Pty) ltd, Republic of South Africa) was administered on Day 9. Heat was observed with the aid of heat mount detectors (Kamar ${ }^{\circledR}$, RSA) which were glued on the tail head of each donor cow and heifer. Day 0 was repeated and a new CIDR was inserted three days after heat observation. On Day 4, two injections of FSH, Folltropin $^{\circledR}-\mathrm{V}(20 \mathrm{mg} / \mathrm{mL}$, Armidale, Australia) were administered at $12 \mathrm{~h}$ intervals every day for 4 days on a decreasing dosage, two injections of prostaglandin were administered $12 \mathrm{~h}$ apart on the last two days of Folltropin $^{\circledR}-\mathrm{V}$. Estrus detection was performed every $8 \mathrm{~h}$ for 3 days starting $24 \mathrm{~h}$ after the second prostaglandin injection. Estrus detection was done with the aid of heat mount detectors.

\section{Semen evaluation and Artificial Insemination}

Semen was collected from two Nguni bulls (bull 1 and 2). The sperm motility rate (non-progressive, progressive, slow, medium and rapid) and the velocity on the curve line were evaluated and recorded using a Sperm Class Analyzer® (SCA-Microptic ${ }^{\circledR}$, Spain) system before AI. Semen from bull 1 and 2 was used to randomly inseminate the cows and heifers. Cows and heifers were artificially inseminated three times (at 12, 24 and $36 \mathrm{~h}$ ) after detection of standing heat with diluted raw semen from stud Nguni bulls of proven fertility.

\section{Embryo Flushing/Grading and Verification}

Rectal palpation was done on both ovaries on day 7 after AI to determine the number of Corpora Lutea (CL) present this was an indicator of whether cows/heifers responded to superovulation. Embryo recovery was immediately performed with a standard non-surgical technique to flush the uterine horns for donors that responded. An epidural anesthesia (Lidocaine, Beyer (Pty) Ltd, Isando and RSA) was injected in the 
intervertebral space between the vertebrae of the tail-head region. The vulva and rectum were thoroughly cleaned before flushing. Flushing of each uterine horn was conducted with a Complete Flush medium, a silicone twoway Foley catheter and a long flushing tube. Retrieved embryos were transferred into an embryo filter containing holding medium and were further evaluated for quality using a stereo-microscope (Olympus SZ40, Olympus, Japan). Embryos were evaluated for the viability and graded excellent, good and fair C1, C2, C1-) according to the International Embryo Technology Society standards their stage of development (i.e., ova, 2-16 cells, early morula, compacted morula, early blastocyst, blastocyst and expanded blastocyst). Excellent and good quality embryos were considered as transferable and others were classified as non-transferable embryos. All transferrable embryos were then vitrified and stored into liquid nitrogen tank $\left(-196^{\circ} \mathrm{C}\right)$ for conservation.

\section{Data Analysis}

The data was analyzed using the Proc (GLM) implemented in the SAS software 2009. The means were compared using one-way Analysis of Variance (ANOVA). The difference between the treatments means were evaluated using the student $t$ - test. The total ova/embryos, transferable embryos and stages of embryo development were tested by ANOVA for the significant differences between the treatments $(\mathrm{P}<0.05)$. Results are expressed as means, standard errors of the means and percentages. Pearson correlations were used for sperm motility and fertilization rate.

\section{Results}

Superovulation response of $40 \%$ was obtained from both cows and heifers and Embryos were classed according to their quality as shown in Table 1. There was a significant difference on the ovary reaction (number of corpora lutea) of cows $(11.3 \pm 1.41)$ and heifers $(4.0 \pm 0.57)$ $(\mathrm{P}<0.05)$. There were no significant differences recorded on the embryo quality recovered between Nguni cows (code 1, 2.5 \pm 1.00 ; code 2, 1.3 \pm 0.59 ) and heifers (code 1, $0.8 \pm 0.41$; code $2,1.0 \pm 0.36)(\mathrm{P}>0.05)$. However, cows had higher numbers of unfertilized ova than heifers $(5.5 \pm 1.05$ and $1.8 \pm 0.47$, respectively) and degenerate embryos (3.7 \pm 1.00 and $1.3 \pm 0.39$, respectively.

The motility characteristics of the spermatozoa from each bull were analyzed for progression and velocity as shown in Table 2. Total sperm motility of 93.7 and 83.5, were observed for bull 1 and 2 respectively. Bull 1 had the highest number of rapidly moving sperm (47.9\%) than bull $2(30 \%)$ however progression was higher in bull 2 $(67 \%)$ than bull $1(62.8 \%)$. Fertilization rates of $67.6 \%$ and $63.5 \%$ were observed following AI with bull 1 and 2 semen respectively. There was a significant positive correlation between TM and fertilization rate as shown in Table 3.

Table 1: Superovulation response and embryo quality between Nguni cows and heifers (Means \pm SE)

\begin{tabular}{|c|c|c|c|c|c|c|c|c|}
\hline \multirow[b]{2}{*}{ Treatments } & \multirow[b]{2}{*}{ Animals (n) } & \multirow[b]{2}{*}{ SO response $(\%)$} & \multirow[b]{2}{*}{ Ovary reaction (\# CL) } & \multirow[b]{2}{*}{ \# Ova } & \multirow[b]{2}{*}{ \# Deg embryos } & \multicolumn{3}{|c|}{ Blastocyst (n) } \\
\hline & & & & & & \# C1 & \# C2 & \# C1- \\
\hline$\overline{\text { Cows }}$ & 15 & $(6 / 15) 40$ & $11.33 \pm 1.41^{\mathrm{a}}$ & $5.50 \pm 1.05^{\mathrm{a}}$ & $3.66 \pm 1.00^{\mathrm{a}}$ & $2.5 \pm 1.00$ & $0.83 \pm 0.41$ & $0.16 \pm 0.04$ \\
\hline Heifers & 10 & (4/10) 40 & $4.00 \pm 0.57^{\mathrm{b}}$ & $1.75 \pm 0.47^{\mathrm{b}}$ & $1.25 \pm 0.39^{\mathrm{b}}$ & $1.25 \pm 0.59$ & $1.00 \pm 0.36$ & $00 \pm 00$ \\
\hline
\end{tabular}

Table 2: Sperm motility characteristics with fertilization rate on super ovulated Nguni cows and heifers (\%)

\begin{tabular}{lllllllll}
\multicolumn{2}{l}{ Table 2: } & Term motility & characteristics with fertilization rate on super ovulated Nguni cows and heifers $(\%)$ & & & & & \\
Bulls & motility & Progressive & Non-progressive & Rapid & Medium & Slow & Static & Fertilization rate \\
\hline Bull 1 & 93.7 & 62.8 & 30.9 & 47.9 & 36.8 & 9.0 & 6.3 & 67.6 \\
Bull 2 & 83.5 & 67.6 & 15.9 & 30.0 & 46.2 & 11.0 & 16.6 & 53.5 \\
\hline
\end{tabular}

Table 3: Correlation of sperm motility characteristic with fertilization rate in Nguni cows and heifers

\begin{tabular}{|c|c|c|c|c|c|c|c|}
\hline Parameters & TM & PM & $\mathrm{NP}$ & RAPID & MD & STATIC & FR \\
\hline$\overline{\mathrm{TM}}$ & $1 ; 00$ & & & & & & \\
\hline PM & $0.378^{\text {ns }}$ & 1:00 & & & & & \\
\hline NP & $0.751^{*}$ & $-0.319^{*}$ & $1: 00$ & & & & \\
\hline RAPID & $0.460^{\mathrm{ns}}$ & $0.973^{* * *}$ & $-0.235^{\mathrm{ns}}$ & $1: 00$ & & & \\
\hline MD & $-0.556^{\mathrm{ns}}$ & $-0.953^{* *}$ & $0.120^{\mathrm{ns}}$ & $-0.960^{* *}$ & $1: 00$ & & \\
\hline STATIC & $-0.990^{\text {*** }}$ & $-0.283^{*}$ & $-0.367^{\mathrm{ns}}$ & $-0.806^{*}$ & $0.488^{*}$ & $1: 00$ & \\
\hline FR & $0.874 * * *$ & $0.763^{* *}$ & $0.340^{\mathrm{ns}}$ & $0.830 *$ & $-0.873 *$ & $-0.823 *$ & $1: 00$ \\
\hline
\end{tabular}

***correlation is significant at $0.001, * *$ correlation is significant at $0.01, *$ correlation is significant at 0.05 , ${ }^{\mathrm{ns}}$ correlations are not significant.TM = total motility, $\mathrm{PM}=$ progressive motility, $\mathrm{NP}=$ Non-progressive motility, $\mathrm{MED}=$ medium and $\mathrm{FR}=$ Fertilization rate 


\section{Discussion}

The results on the response of Nguni cows and heifers to superovulation showed no significant difference as it was $(40 \%)$ on both. Similar results were reported for dairy cows and heifers where there were no differences on the superovulatory response of cows and heifers (Bo et al, 2009). No significant differences were observed amongst the Nguni cows and heifers when the numbers of transferable embryos were compared. Similarly, Nilchuen et al. (2011) reported that there were no significant differences in the quality of embryos flushed from Kamphaeng Sean cows and heifers after receiving FSH treatment. The large difference on the number of embryos flushed was speculated to be due to individual animal variations.

The ovary reaction (number of CL), total number of unfertilized ova and degenerate embryos were greater on the Nguni cows than heifers even though overall superovulation response was similar among these two groups. The greater number of CL were reported to be mostly in heifers than dairy cattle since their progesterone levels are higher as lactating cows have distress from negative energy balance. Interestingly, Degefa et al. (2016) reported that Bosindicus compared with Bostaurus cattle have higher circulating concentrations of ovarian steroid hormones (e.g., estradiol and progesterone), larger population of small diameter ovarian follicles and smaller size of the dominant follicle. Cows used in this study were not lactating and in an acceptable body condition ranging between (BCS;3-4) on a scale of 1-5. Individual animal variations and the unnatural process of superovulation might have an effect on the different superovulation response because under normal breeding programs the physiology of a cow allows one egg to be released per cycle (Mapletoft et al., 2002). In superovulation females are provided with FSH in order to recruit high numbers of follicles that will be selected at ovulation, this happens when FSH is bound on the receptors in the ovary. According to Nilchuen et al. (2011) when the dosage is higher, less ovarian reaction can be observed due to fewer receptors to withstand the reaction. The heifers used in the present study weighed less than the cows and yet received similar amount of FSH, chances of the dose being unsupported by the ovary were high. Overstimulation has been reported to result in Ana ovulatory follicles and hence reduced ovary reaction and fertilization rate since the Bos indicus breeds require less dosages of superovulation treatments than Bos taurus (Sartori et al., 2009; Kafi and McGowan, 1997). Furthermore, a lesser dose 200 and $240 \mathrm{mg}$ were used for heifers and cows respectively in a study on Brahman cattle and $200 \mathrm{mg}$ was reported to be the appropriate dose as better results were obtained (Bertens, 2010). According to Barati et al. (2006), a greater number of CL was expressed by the heifers that received $200 \mathrm{mg}$ of Follotropin. However, this is a lesser dose than the recommended $400 \mathrm{mg}$ for Bos taurus breeds. Heifers require less dosage of FSH than cows because of the body weight and size. The Sanga breeds are reported to have delayed puberty than the exotic breeds and Sanga heifers are not mated until three to four years and heifers used in this study were 2 years and this might have affected and reduced the ovary reaction (Krininger et al., 2003; Schoeman, 1989). The Bos indicus breeds are generally small framed with also very small body organs with heifers the ovaries are very small even after superovulation the chances of miscounting the CL during rectal palpation were maximized, similarly, in Nelore cows and heifers the CL was reported to be small (Gonzalez et al., 1994). Super stimulation using FSH requires a lot of attention because two injections are given to the donors in one day this may results in undue stress to the cows and stress might result in lower responses in donors that are not used to being handled daily such as Nguni cattle breed (Bo et al., 2009).

The eCG is a complex glycoprotein that is used as a traditional way of super ovulating the donors. The use of eCG has been reported to be very quick and effective (Lane et al., 2008; Bo et al., 1996). A single administration of eCG was reported to induce ovarian superovulation and thus minimize stress. In the present study, FSH protocol was used because of improvement in the protocol that ensures that the emergence of the follicular wave and timing of ovulation occur at the same time in the donors and a fixed AI is guaranteed (Marquezini et al., 2013; Lopes da Costa et al., 2001; Lane et al., 2008). The uniformity that the protocol improvement has brought has been reported to have positive effects on commercial embryo transfer and breeding programmes (Hasler, 2010). The complexity that is sometimes found on the superovulation protocols brings about variability in the superovulatory response (Figueiredo et al., 1997). The poor quality of the CL at the time of embryo transfer, as determined by palpation is reported to affect pregnancy (Chang et al., 2006). Lower progesterone levels on the recipient cows on the time of ET results in lower pregnancy rates. The quality of embryos is reported to be the major factor reducing pregnancies however variables from females can also be observed (Silva et al., 2002). Krininger et al. (2003) reported that conception rates of more desirable quality embryos (excellent or good) are greater than embryos qualified as fair or poor quality; therefore, conception rates would increase if a greater percentage of grade 1 (excellent) embryos are harvested and transferred after collection.

In current AI practices, an important element is accurate and precise quality assessment of the motility characteristics of spermatozoa (Broekhuijse et al., 2015). This study demonstrated that there was a positive correlation between total sperm motility, rapid, progressive and non-progressive with fertilization rate. 
Results found in this study are comparable with findings by Seshoka et al. (2016) where positive correlation between total sperm motility and pregnancy rate $(0.42)$ was recorded. It was not surprising to observe a negative correlation of non-progressive (static) and Medium (MED) movement sperm with fertilization rate.

The results for fresh semen are usually higher depending on the fertility of the bulls used. Poor motility is reported as a good predictor of failure in fertilization (Pursley et al., 1995). This study reported a significant positive correlation coefficient between rapid moving spermatozoa and fertilization rate this finding is similar to results by Vasan (2011). Dalton et al. (2000) reported higher fertilization rate when donors were inseminated $24 \mathrm{~h}$ after the onset of oestrous compared to inseminations at 0 or $12 \mathrm{~h}$, in this study cows and heifers received three doses of semen at 12, 24 and $36 \mathrm{~h}$. It was speculated that these differences might have occurred due to decreasing fertilization potential of sperm before ovulation occurred.

\section{Conclusion}

There was a positive relationship between total sperm motility, rapid and progressive with fertilization rate. Furthermore, Nguni cows and heifers can be super ovulated successfully, the response rate was not different between cows and heifers although it resulted in lower number of transferable embryos. Ovary reaction was higher on the cows; however, it did not translate into higher number of embryos recovered. Further studies are recommended on the superovulation of South African indigenous cattle.

\section{Acknowledgement}

The authors would like to thank the Agricultural Research Council's germplasm conservation and reproduction technologies for technical support

\section{Funding Information}

This study was funded by the Technology Innovation Agency (TIA), Agricultural Research Council (ARC) and Govan Mbeki Research Development Centre (GMRDC).

\section{Author's Contributions}

All authors equally contributed in this work.

\section{Ethics}

This article is the original work containing unpublished data. All authors read and approved the manuscript.

\section{References}

Barati, F., Niasari-Naslaji, A., Bolourchi, M., Sarhaddi, F., Razavi, K., Naghzali, E., \& Thatcher, W. W. (2006). Superovulatory response of Sistani cattle to three different doses of FSH during winter and summer. Theriogenology, 66(5), 1149-1155. doi.org/10.1016/j.theriogenology.2006.03.026

Baruselli, P. S., de Sá Filho, M. F., Martins, C. M., Nasser, L. F., Nogueira, M. F., Barros, C. M., \& Bó, G. A. (2006). Superovulation and embryo transfer in Bos indicus cattle. Theriogenology, 65(1), 77-88. doi.org/10.1016/j.theriogenology.2005.10.006

Bertens, M. F. (2010). Comparison of corpus luteum function and embryo quality in heifers and second/third parity lactating cows. https://dspace.library.uu.nl/handle/1874/178945

Bo, G. A., Adams, G. P., Pierson, R. A., \& Mapletoft, R. J. (1996). Effect of progestogen plus estradiol-17 $\beta$ treatment on superovulatory response in beef cattle. Theriogenology, 45(5), 897-910. doi.org/10.1016/0093-691X(96)00020-9

Bó, G. A., Guerrero, D. C., Tríbulo, A., Tríbulo, H., Tríbulo, R., Rogan, D., \& Mapletoft, R. J. (2009). New approaches to superovulation in the cow. Reproduction, Fertility and Development, 22(1), 106-112.

Broekhuijse, M. L. W. J., Šoštarić, E., Feitsma, H., \& Gadella, B. M. (2012). Application of computerassisted semen analysis to explain variations in pig fertility. Journal of Animal Science, 90(3), 779-789. https://academic.oup.com/jas/articleabstract/90/3/779/4764515

Chang, Z., Fan, X., Luo, M., Wu, Z., \& Tan, J. (2006). Factors affecting superovulation and embryo transfer in Boer goats. Asian-australasian journal of animal sciences, 19(3), 341-346. doi.org/10.5713/ajas.2006.341

Dalton, J. C., Nadir, S., Bame, J. H., Noftsinger, M., \& Saacke, R. G. (2000). The effect of time of artificial insemination on fertilization status and embryo quality in superovulated cows. Journal of animal science, 78(8), 2081-2085. doi.org/10.2527/2000.7882081x

Degefa, T., Lemma, A., Tegegne, A. Youngs, C.R. 2016. Superovulation of Boran Cattle in Ethiopia: A Preliminary Report. Iowa State University: Animal Industry Report.

Silva, J. C., da Costa, L. L., \& Silva, J. R. (2002). Embryo yield and plasma progesterone profiles in superovulated dairy cows and heifers. Animal reproduction science, 69(1-2), 1-8. doi.org/10.1016/S0378-4320(01)00172-5 
Seshoka, M. M., Mphaphathi, M. L., \& Nedambale, T. L. (2016). Comparison of four different permitting and combination of two best cryoprotectants on freezing Nguni sperm evaluated with the aid of computer aided sperm analysis. Cryobiology 72(3), 232-238.

Figueiredo, R. A., Barros, C. M., Pinheiro, O. L., \& Soler, J. M. P. (1997). Ovarian follicular dynamics in Nelore breed (Bos indicus) cattle. Theriogenology, 47(8), 1489-1505. doi.org/10.1016/S0093-691X(97)00156-8

Gonzalez, A., Wang, H., Carruthers, T. D., Murphy, B. D., \& Mapletoft, R. J. (1994). Superovulation in the cow with pregnant mare serum gonadotrophin: Effects of dose and antipregnant mare serum gonadotrophin serum. The Canadian Veterinary Journal, 35(3), 158. https://www.ncbi.nlm.nih.gov/pmc/articles/pmc16 $86325 /$

Hasler, J. F. (2010, August). Bovine embryo transfer: Are efficiencies improving. In Applied Reproductive Strategies Conference Proceedings August 5th \& 6th, Nashville, TN (pp. 265-282).

https://beefrepro.org/wp-

content/uploads/2020/09/2012ARSBC_25HaslerPro ceedings.pdf

Kafi, M., \& McGowan, M. R. (1997). Factors associated with variation in the superovulatory response of cattle. Animal reproduction science, 48(2-4), 137-157. doi.org/10.1016/S0378-4320(97)00033-X

Krininger III, C. E., Block, J., Al-Katanani, Y. M., Rivera, R. M., Chase Jr, C. C., \& Hansen, P. J. (2003). Differences between Brahman and Holstein cows in response to estrus synchronization, superovulation and resistance of embryos to heat shock. Animal reproduction science, 78(1-2), 13-24. doi.org/10.1016/S0378-4320(03)00045-9

Lane, E. A., Austin, E. J., \& Crowe, M. A. (2008). Oestrous synchronisation in cattle-Current options following the EU regulations restricting use of oestrogenic compounds in food-producing animals: A review. Animal Reproduction Science, 109(1-4), 1-16. doi.org/10.1016/j.anireprosci.2008.08.009

Lopes da Costa, L. (2001). Superovulatory response, embryo quality and fertility after treatment with different gonadotrophins in native cattle. Theriogenology, 56(1), 65-77. doi.org/10.1016/S0093-691X(01)00543-X
Mapletoft, R. J., Steward, K. B., \& Adams, G. P. (2002). Recent advances in the superovulation in cattle. Reproduction Nutrition Development, 42(6), 601-611. doi.org/10.1051/rnd:2002046

Marquezini, G. H. L., Mercadante, V. R. G., Olson, K. C., Jaeger, J. R., Perry, G. A., Stevenson, J. S., \& Lamb, G. C. (2013). Effects of equine chorionic gonadotropin on follicle development and pregnancy rates in suckled beef cows with or without calf removal. Journal of animal science, 91(3), 1216-1224.

https://academic.oup.com/jas/articleabstract/91/3/1216/4717226

Nedambale, T. L. (2012). Business newspaper http://www.fin24.com

Nilchuen, P., Rattanatabtimtong, S., \& Chomchai, S. (2011). Superovulation with different doses of follicle stimulating hormone in Kamphaeng Saen beef cattle. Songklanakarin J. Sci. Technol, 33(6), 679-683. https://rdo.psu.ac.th/sjstweb/journal/33-6/01253395-33-6-679-683

Nqeno N, Chomonyo M, Mapiye C, Marufu MC (2010). Ovarian activity, conception and pregnancy patterns of cows in the semiarid communal rangelands in the Eastern Cape Province of South Africa. Animal Reproduction Science 118(2):140-147.

Pursley, J. R., Mee, M. O., \& Wiltbank, M. C. (1995). Synchronization of ovulation in dairy cows using PGF2 $\alpha$ and GnRH. Theriogenology, 44(7), 915-923. doi.org/10.1016/0093-691X(95)00279-H

Sartori, R., Bastos, M. R., \& Wiltbank, M. C. (2009). Factors affecting fertilisation and early embryo quality in single-and superovulated dairy cattle. Reproduction, Fertility and Development, 22(1), 151-158. doi.org/10.1071/RD09221

Schoeman, S. J. (1989). Recent research into the production potential of indigenous cattle with special reference to the Sanga. South African Journal of Animal Science, 19(2), 55-61.

https://www.ajol.info/index.php/sajas/article/view/1 38948

Tada, O., Muchenje, V., Dzama, K. 2013. Reproductive efficiency and herd demography of Nguni cattle in village-owned and group-owned enterprises under low-input communal production systems. Tropical Animal Health Production 45(6):1321-9

Vasan, S. S. (2011). Semen analysis and sperm function tests: How much to test?. Indian journal of urology: IJU: Journal of the Urological Society of India, 27(1), 41. doi.org/10.4103/0970-1591.78424 